\title{
Some French Amateurs of the 2nd Half of the 19th Century
}

\section{Françoise Hourmat}

Residence Concorde, 13 square St. Florentin, F-78150 Le Chesnay, France

At that period there was keen popular interest in astronomy, and in many Paris squares, astronomers with terrestrial refractors gave talks on astronomy for a small sum. Léon Joubert created a observatory for scientific research and popularisation, allowing anyone to learn about the universe and use good instruments. He made 120 instruments: refractors, reflectors, projectors, and photographic instruments.

Hermann Goldschmidt (1802-1866), born at Frankfurt am Main 17 June 1802, had poor health, became a painter and sought his fortune in Paris. He became an astronomer by accident after following a course of lectures at the Sorbonne given by Le Verrier. From a modest studio on the 6th floor of an old house in the heart of Paris, he discovered 14 minor planets between 1852 and 1861, the first being called Lutetia by Arago.

At Vaison (Vaucluse) Father Gaudibert (1823-1901) made observations of the Moon and various discoveries about rilles and craters that were published in $\mathrm{Me}$ chanic, l'Astronomie and the Bulletin of the S.A.F.

The doctor Edmond Lescarbault (1814-1894) lived at Orgères (Eure et Loire), $100 \mathrm{~km}$ west of Paris and built a small observatory on his house. On 26 March 1859 he saw a black dot against the limb of the Sun. Its passage across the Sun took $1 \mathrm{hr}$ 17 mins 22 secs (siderial time). He thought that he had discovered the planet sought by Le Verrier to account for the perturbation of Mercury, but no one has ever seen the object again.

Amédée-Victor Guillemin was a journalist and scholar, who published twenty popular science books. He was up-to-date with the latest progress because he corresponded with research workers. His clear style and his well-illustrated book greatly helped to popularize astronomy. 